\title{
PHONOLOGICAL PHRASING IN GERMANIC: THE JUDGEMENT OF HISTORY, CONFIRMED THROUGH EXPERIMENT
}

\author{
By Aditi Lahiri and Frans Plank \\ University of Oxford and Universität Konstanz
}

\begin{abstract}
There are contrary views on how phonological phrasing in Germanic is determined: either by surface syntax or by rhythmic principles (forming trochaic/dactylic or iambic/ anapaestic groupings) or alternately by both depending on speech style (spontaneous/ planned, casual/careful). It is shown in this paper that a host of historical developments in Germanic - having to do with cliticisation and the creation of new inflectional affixes from clitics, and with attendant changes of the forms involved - point to a default phonological phrasing of grammatical/function words which associates them leftwards regardless of morphosyntactic constituency and which does not respect morphological word integrity either. Thus, encliticisation predominates almost exclusively, and productive inflectional affixes innovated via cliticisation are all suffixes. Experimental evidence from contemporary Germanic (in this case Dutch) confirms that phonological words are crucial units in speech planning, with such units equally formed as trochees irrespective of the phrasal syntax of grammatical and lexical words.
\end{abstract}

\section{CONTRARY VIEWS ON HOW PHONOLOGICAL PHRASING IS DETERMINED}

\subsection{Constructions and their parts: morphosyntax in relation to semantics}

If you want to think and express a thought, you will be guided not only by the laws and vagaries of thinking, but also by the lexicon and grammar of your language. Although our concern subsequently will chiefly be with the latter, it is an interesting question how a thought as such takes shape in real time in the mind of the thinker, especially if it is a complex thought - say, the thought (often thought and expressed, among many others, by Alexander Pope ${ }^{1}$ ) that the sound must seem an echo to the sense. It is probably not unreasonable to assume that the parts which come first in the real-time construction of this thought, especially if embedded in a general train of thought about the relationship between form and meaning, are the concepts of sound and of sense and the concept of an asymmetric correspondence relation between them - for which the English lexicon provides the noun-or-verb words sound, sense and echo, respectively. The concepts of seeming (as opposed to being) and of deontic necessity, expressible in English through a verb seem and a modal auxiliary must, would seem secondary, in the sense of not normally being the primary topics when such a thought is being thought and expressed - unless they have gained importance and planning priority as a focus of contrast. The temporal embedding of the thought (something of a timeless directive) and the contextual embedding of its parts (sound and sense as contextually given) are an everpresent mould for thinking - at least when the thinking is being done by speakers of English.

\footnotetext{
${ }^{1}$ In his Essay on Criticism (1711) - which is in fact a poem. Its metre is supposed to be the iambic pentameter; but arguably a trochaic reading of this line, and many others, is preferable - as per (4b) below. 
Yet another real-time question is whether the formation of a thought must be completed before the thinker can begin to express it, in English or any other language. In the case of thoughts which are complex and deep (though still one thought rather than several), and whose formation is therefore protracted rather than instantaneous, the business of expression will conceivably be initiated before the thinking of the thought has been completed. Conversely - since thoughts typically do not occur on their own, but are joined with others in arguments, narratives or dialogic exchanges - it is probable that the forming of a whole train of thoughts, or at least of certain thematic connections and developments between successive thoughts, will be completed before the actual expression of one after the other commences. In other words, there is an empirical question here concerning the real-time relationship between the progress of thinking thoughts and of expressing them. It may all depend on the kinds of thoughts, on the kinds of thinkers, and on their styles of thinking and speaking. ${ }^{2}$

Matters are further complicated insofar as the expression of thoughts is not done in one go with even the simplest of thoughts. With various degrees of sophistication, any modelling of thought-expression has distinguished two main stages of articulation after forming a thought, INVENTIO: ${ }^{3}$ first DISPOSITIO, with suitable items chosen from the lexicon and combined according to the rules and constraints of grammar; then ELOCUTIO, with grammatical constructions translated into sound (or sign). Concerning real-time processes the overall question, then, is how the progress of ELOCUTIO relates to that of DisPositio and how both relate to the progress of INVENTIO. Do they strictly come one after the other, with each step thought-INVENTIO, thought-DISPOSITIO, thought-ELOCUTIO - completed before the next is begun? And - this is the only and comparatively simple question that we propose to address here what are the INVENTIO-parts of a proposition (semantics), the DISPOSITIO-parts of a sentence (morphosyntax), and the ELOCUTIO-parts of an utterance (phonology), and how are they related to one another?

Returning to our example of the thought that the sound must seem an echo to the sense, it would seem that semantic and morphosyntactic constructions are partly isomorphic and partly non-isomorphic - although to some extent this impression will depend on how one prefers to do semantics, while constituency in morphosyntax is generally easier to agree on: ${ }^{4}$

(1) semantic grouping:

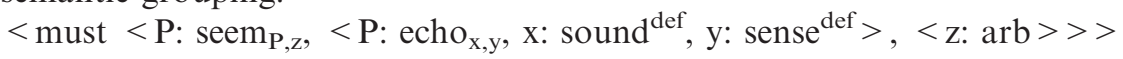

(2) morphosyntactic grouping:

$\left[\left[\right.\right.$ The $_{\text {Gram }}$ sound $\left._{\text {Lex }}\right]\left[\left[\right.\right.$ must $_{\text {Gram }}$ seem $\left._{\text {Lex }}\right]\left[\left[\operatorname{an}_{\text {Gram }}\right.\right.$ echo $\left._{\text {Lex }}\right]\left[\left[\right.\right.$ to $_{\text {Gram } / \text { Lex? }}\left[\right.$ the $_{\text {Gram }}$ sense $\left.\left.\left.\left.\left._{\text {Lex }}\right]\right]\right]\right]\right]$

In the sort of semantic representation given here, the way predicates $(\mathrm{P})$ are related to their $\operatorname{arguments}(\mathrm{x}, \mathrm{y}, \mathrm{z})-\mathrm{a}$ proposition and an argument with arbitrary reference (overtly unexpressed) in the case of 'seem', two definite referents in the case of 'echo' - is not precisely mirrored by syntactic constituency. Also, the deontic necessity operator operates on the whole proposition in the semantic representation, while its morphosyntactic counterpart, the modal must, is closely associated with just the main verb. More faithfully, the overt markers of definiteness (definite and indefinite articles) and the relational marker for the second argument

\footnotetext{
${ }^{2}$ Though not a linguist or psychologist but a fine writer, who would turn and punctuate his phrases with utmost care, Heinrich von Kleist once made a good case against separateness and sequentiality in 'Über die allmähliche Verfertigung der Gedanken beim Reden' (1805).

${ }^{3}$ To use the terminology of classical rhetorics. A milestone in contemporary modelling would be Levelt's Speaking (1989): but the stages have remained essentially the same.

${ }^{4}$ Angle and square brackets show semantic and syntactic grouping, respectively. We trust it will not cause confusion when angle brackets are, sparingly, also used for phonetic transcription.
} 
of 'echo' are associated with the respective argument or also predicate expressions in English. Tense also has propositional scope meaning-wise, but would have to be morphologically associated with the verbal part - except in this example there is no overt tense marker visible on either must or seem.

The matching or mismatching of the parts of constructions across different kinds of representations, of meaning and of form, is our general theme here. A first conclusion is that they can mismatch from INVENTIO to DISPOSITIO, from semantics to morphosyntax.

\subsection{Constructions and their parts: phonology in relation to morphosyntax}

Now, when a worded-up and morphosyntactically constructed proposition is pronounced (ELocutio), how will it be grouped phonologically? This is a familiar sub-issue of the general matching-or-mismatching question; yet the answers given for familiar languages like English have been remarkably contradictory.

\subsubsection{Theories}

There are two schools of thought concerning phonological phrasing at the levels between those of word and clause in Germanic. ${ }^{5}$ One school holds that phonological phrasing is essentially determined by (surface) syntactic constituency; the opposite view is that phonological phrasing is essentially independent of syntactic constituency, and is as it were rhythmic. Since the appearance of two seminal publications, Selkirk (1984) (with Selkirk 1995/1996 as an important early sequel) and Nespor \& Vogel (1986), syntactic determinism has become the standard contemporary view, widely accepted as self-evidently correct and usually only updated in details and revised in technicalities of its implementation in changing descriptive frameworks (e.g. Truckenbrodt 1999). ${ }^{6}$

However, a view diametrically opposed to current orthodoxy was once equally predominant. It was originally propagated by such important phoneticians-cum-prosodists as Joshua Steele (1775/79), Henry Sweet (1876; 1877; 1885; 1887) and Eduard Sievers (1901a; 1901b), for English, German, and a range of further languages, mostly Germanic. Sweet (1885/1904), for instance, instructing Germans in correct southern British English pronunciation, would generally phrase as in this example ${ }^{7}$ - where the stressed syllables of content words form the left edge of 'tone groups', which then include everything up to the next stressed syllable:

(3) (When there is a) (strong) (wind) (blowing) (towards the) (land) wenðəzə stron wind blowin todzðə lænd

This kind of phrasing utterances into 'cadences' (Steele's term), 'tone groups' (Sweet), or 'Sprechtakte' (Sievers) independent of syntax was adopted by leading grammarians such as Hermann Paul (1916-20) for German or Karl Luick (1923) for Austrian German. It was

\footnotetext{
${ }^{5}$ 'Phonological phrasing' is here used as a cover term for grouping at all levels of the prosodic hierarchy. The focus subsequently will mostly be on the level of the phonological word.

${ }^{6}$ Such a neat correspondence is also taken for granted in frameworks where syntactic representations are assumed to be constructed in 'phases', with the phonological interpretation proceeding phase by phase (e.g. Kratzer \& Selkirk 2007). It should be added that some proponents of syntactic determinism have lately adopted a less deterministic position, sometimes withdrawing so far as to merely assume that 'prosodic structure ... is influenced by syntactic structure' (Truckenbrodt 2007: 455, our emphasis) - which nobody would deny. Others have remained true-blue syntactic determinists, but have made it more explicit that isomorphism is supposed to reign at the level of phonological words, but not necessarily at those of phonological phrases and beyond (e.g. Selkirk \& Elordieta 2010).

${ }^{7}$ Given in Sweet's own Broad Romic transcription in the second line: spaces indicate tone-group boundaries, no spaces their absence. We normally use round brackets for phonological phrasing.
} 
greatly elaborated by Sievers' student, Franz Saran (1907; 1934), who worked out a prosodic hierarchy in unrivalled detail. And in one form or another it has continued to be occasionally advocated in theory and practice (e.g. Abercrombie 1964a; 1964b; Gimson 1962; Fudge 1999 for English; Eisenberg 1998 for German; Fretheim 1981; 2001 for Norwegian). ${ }^{8}$

To illustrate the difference between the two approaches with our example, the English sentence whose surface-syntactic constituency, uncontroversially, is as in (2) would alternatively be expected to be phonologically phrased as in (4a) or in (4b), with prominent utterance parts (stressed syllables) capitalised and the last unit ending with an empty beat ' $\bullet$ ':

(4) a. (the SOUND) (must SEEM) (an EC.cho) (to the SENSE)

b. the (SOUND must) (SEEM an) (EC cho) (TO the) (SENSE •)

In (4a), the phonological phrasing essentially follows the surface syntax. As to syntax itself, in bare essence and regardless of subtleties of individual descriptive approaches, the predominant pattern just about everywhere in Germanic is that syntactic phrases are made up of grammatical or function words (a heterogeneous lot) and lexical or content words (nouns, verbs, adjectives, some adverbs, some adpositions, perhaps some pronouns too) and the grammatical words quite consistently precede the lexical words (or lexically headed phrases) they are in construction with:

(5) a. DET - N (with definite and indefinite the sound; a sound; no sound; this sound; articles, demonstratives, and such sounds; my sound possessives as prototypical DET's):
b. $\mathrm{QU}-\mathrm{N}$ :
c. PARTICLE - N:
d. $A U X-V$ :
e. $\mathrm{ADV}-\mathrm{A} / \mathrm{V}$ :
f. PREP - NP:
g. CONJ - CONJUNCT:
h. COMP - VP/CLAUSE:

both sounds; five sounds

only sounds

can hear; has heard; was heard

very loud; more/most beautiful; (we)

almost lost

with sounds

fish [and chips]; old [and infirm]; come

[and go]; [either fish] [or chips]

to come; that/if/why they come

There are instances of grammatical words coming after their lexical words, but they are comparatively rare, and sometimes involve what might be analysed as 'movement':

(6) a. verb PARTICLES in English:

b. the occasional POSTP:

c. NEG after AUX in English:

d. NEG after main $\mathrm{V}$ in earlier English:

e. NEG after V or AUX with finite-verb-second in German:

f. AUX after $\mathrm{V}$ with finite-verb-final in German:
[Put on] a coat

years ago; such examples aside (or: aside

from such examples)

you [must not] lie (as different from you must [not lie])

I know not

$d u$ [darfst nicht] lügen 'you [must not] lie', as opposed to finite-verb-final order, where NEG is before $\mathrm{V}$ : weil du nicht lügen darfst 'because you not lie must' weil du nicht [lügen darfst]

\footnotetext{
${ }^{8}$ For a historiographic reminder see Plank (2005).
} 


\section{g. certain focus PARTICLES: Otto selbst 'Otto himself' (with stress on final PRTCL), as opposed to selbst Otto 'even Otto' (stress on N) \\ h. 'floated' QU: the books both (with stress on floated QU), as opposed to both books (stress on $\mathrm{N}$ )}

In this sense, syntactic grouping can itself be called iambic: within one unit of construction, weak (Gram) comes before strong (Lex). This characterisation is all the more apt as syntacticsemantic weakness and strongness (grammatical vs. lexical words) will normally be reflected prosodically, with prominence, in the form of main phrasal stress, typically on lexical words rather than on grammatical words. (Contradicting this expectation of a meaning-form correspondence, the prosodic prominence pattern is weak-strong in some of the instances of Lex-Gram in (6), too.)

In syntax-determined phonological phrasing, now, allowances would be made for certain adjustments, like that of flattening hierarchical syntactic constituent structures, in general and especially after a focused constituent, and of redressing imbalances between overly weak and strong co-constituents, such as a mere indefinite article on the one hand and a recursively modified noun on the other (as in (7), where the phonological phrasing would be $\left(7 b^{\prime}\right)$ rather than (7b), entirely faithful to syntax). Importantly, however, there would be no re-phrasings across morphosyntactic phrase boundaries on this approach.

(7) a. [Drink [a [pint [of milk]]] [a day]]

b. (DRINK (a (PINT (of MILK))) (a DAY))

$b^{\prime}$. (DRINK ((a PINT) (of MILK)) (a DAY))

In stark contrast to syntactic determinism, the syntax is blatantly disregarded in (4b), and the utterance is instead divided up into parts which begin with a strong and typically end with a weak constituent, thus forming the rhythmic pattern of trochees or also dactyls (sometimes with initial weak syllables left unphrased, i.e. with anacrusis). On this view, phonological phrasing, at all levels of complexity, is seen as independent of morphosyntactic constituency except insofar as it respects (i) clause boundaries (reflecting major planning units); (ii) the distinction between lexical and grammatical morphemes (the former come with inherent prominence, assigned at word-level); (iii) perhaps inherent weight (quantity, branchingness); and (iv) focus (which also adds prominence, and perhaps attenuates prominence in parts following the focus). What is not respected, on this view, is the integrity of morphological words: initial weak (unstressed) syllables are phrased with a strong (stressed) syllable preceding them across morphological word boundaries. Here are some examples from the literature, with verbal prefixes $g e-(8 \mathrm{a}, 8 \mathrm{~b}, 9 \mathrm{a})$, be- (8b), adjectival prefix on- $(9 \mathrm{~b})$, it in the compound itself (10), and non-morphemic initial syllables An in Antonia (8b), pe in peculiar, $m u$ in musicians (10), and $a$ in aprille (11) assumed to be prosodically disattached:

(8) German (Sievers 1901a)

a. [Alle Hoffnungen] [[sind] [ihm] [ge-scheitert]]

(AL.le) (HOFF.nuy.gen) (SINT ihm ge) (SCHEI.tert)

'All hopes have failed him.'

b. [Niemals] [hätte] [ich] [[ge-glaubt], [[so] [von An.tonia] [be-trogen [zu werden]]]] (NIE.mals hät.te ich ge) (GLAUBT) $\mid$ (SO von an) (TO.ni.a be) (TRO.gen zu wer.den) 'Never would I have believed to be so betrayed by Antonia.' 
(9) Dutch (Sweet 1877)

a. [Heb] [je] [goed ge-slapen]?

(HEB je) (GOED ge) (SLA.pen)? ${ }^{9}$

'Have you slept well?'

b. [De koude] [maakt [de luiheid] on-mogelijk]

(De) (KOU.de) (MAAKT de) (LUI.heid on) (MO.ge.lijk) ${ }^{10}$

'The cold made the laziness impossible.'

(10) 18th century English (Steele 1775: 28, omitting much notational detail)

(Every) (sentence) (in our) (language), (whether) (prose or) (verse •),

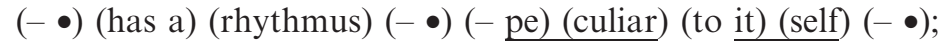

(that is, in the) (language of) (modern mu) (sicians), (- it is)

(either in) (common time) (- or) (triple time); (- vi) (delicet),

(minuet time), (- or) (jigg time), (- or) (mixed $\bullet$ ).

(11) Middle English (Sweet 1887, with his Broad Romic transcription unaltered)

:whan:pata prille :wipis Juures swoote

-pe druxtof mart -hap persedtoope roote

'When [that] April with his showers sweet

The drought of March has pierced unto the root'

(Chaucer, General Prologue of The Canterbury Tales)

\subsubsection{Experiments}

By now there is a substantial body of experimental work on phonological phrasing especially in English. However, looking at it collectively, the evidence is as equivocal as is the theoretical literature.

On the one hand, experimental work on speech production and perception inspired by the theoretical approaches of Selkirk and Nespor \& Vogel would typically find that phonological phrasing - especially as established in terms of the lengthening of pre-boundary syllables (or also of the duration of 'interstress intervals') and of the strength of perceived 'break indices' (the perceived degree of separation between adjacent words) - is essentially isomorphic to surface-syntactic constituency. Representative of this line of research are Price et al. (1991), Wightman et al. (1992), De Pijper \& Sanderman (1994), Watson \& Gibson (2004). ${ }^{11}$ Here, as an example, are break indices ranging from 0 to 6 as found by Price et al. (1991), which could not be closer to surface-syntactic constituency:

(12) Only $\mathbf{1}$ one $\mathbf{4}$ remembered $\mathbf{3}$ the $\mathbf{0}$ lady $\mathbf{1}$ in $\mathbf{1}$ red $\mathbf{6}$

[only one] [remembered [the [lady [in red]]]]

On the other hand, it was noted again and again that - sometimes or indeed oftentimes phonological and syntactic phrasings are not isomorphic, with the former significantly influenced by purely rhythmic factors in speech production, such as the tendency to avoid

\footnotetext{
${ }^{9}$ In Sweet's own transcription: ghutghe, with syllable-final devoicing of the adjective's coda plus progressive devoicing of the prefix's onset (with $g h$ a voiceless fricative, as always in northern Dutch, but only upon assimilation in southern Dutch).

${ }^{10}$ Sweet's transcription: maigddeh, with regressive assimilation.

${ }^{11}$ Also see the overview in Patel (2008).
} 
groups that are very short or very long or the tendency to balance the length of groups. Representatives of this camp include Gee \& Grosjean (1983), Ferreira (1991), and ShattuckHufnagel \& Turk (1996). There has been a tendency to interpret such discrepancies as secondary interferences with a basic isomorphic phrasing algorithm, and not as throwing doubt on the basic validity of that algorithm. There are not many studies like that of Wenk \& Wiolland (1982), where English is found to be fundamentally trochaic (in very much a SteeleSweet-Sievers-Saran sort of way), rather than only by interference, as opposed to iambically phrasing French:

(13) (PHILlip is (STUdying at the uni (VERsity

PhilLIPPE) étuDIE) à l'universiTÉ)

For processing, a 'metrical segmentation strategy' was observed by Cutler \& Norris (1988), (also Cutler 1994), which would posit a word onset at each strong syllable in English, regardless of morphosyntactic constituency, thus accounting for slips of the ear such as this:

(14) by LOOSE aNAlogy

by LUCE and ALlergy misheard/missegmented

\subsubsection{Agreeing to disagree?}

This disagreement over the determination of phonological phrasing in English and elsewhere in Germanic is of long standing and continues to be unresolved, both theoretically and experimentally. It is a sort of disagreement which is not in fact confined to Germanic scholarship: it is only that Germanic languages have long played an inspirational role in prosodic theorising, and hence the disagreement is most visible in this arena.

When there is persistent disagreement, one reason could be that it is not really a major concern whether things are one way or another. An alternative reason could be that both sides have it right.

As to the first possible reason: does really little or nothing depend on whether utterances are phonologically phrased as dictated by morphosyntax or by rhythm? The resulting phonological phrase domains are different, and the questions therefore are where boundary markers are located if there are any, and which and how many phonological or phonetic processes are bounded in terms of such domains. The boundary markers at issue are boundary tones and the pre-boundary lengthening of syllables, rather than actual pauses (which rather delimit domains higher than phonological phrases). Processes which are relevant here include consonantal assimilations and deletions, vowel reductions or also epenthesis, and the syllabification of final consonants. Consider (15):

(15) a. (DRINK) (a PINT) (of MILK) (a DAY)

b. (DRINK a) (PINT of) (MILK a) (DAY •)

$$
\text { lov/ }>\text { /a/ }
$$

The reduction of $/ \mathrm{ov} /$ to $/ \mathrm{\partial} /$, involving the deletion of a coda consonant and the attenuation of the remaining vowel, is a more plausible process in context (16b) than in (16a), after a stressed syllable in close association with a preceding consonant resyllabified, rather than 
before a stressed syllable with no resyllabification of the final consonant even when preceding a vowel-initial word: ${ }^{12}$

(16) a. /ov.'mılk/, /ov.'erl/ of ale

b. /'pain.tov/, /'pain.tə/

Owing to the reluctance of final consonants of weak constituents (such as prefixes) to resyllabify across morphological or syntactic boundaries in Germanic, even in the smallest phonological domains, the bonding will always tend to be tighter between strong constituents and following weak constituents than with any weak constituents that precede them. Prefixed verbs in German, for instance, do not allow resyllabification and enforce a glottal stop indicative of lexical word onset: be-PANTworten lit. 'to be-answer', ent-?EHren 'to dis-honour'. ${ }^{13}$ (This raises the issue of what is cause and effect: the resyllabification asymmetry or the phrasing direction asymmetry, as will be outlined presently.) All in all, it would seem anything but negligible for languages of Germanic cut where the phonological phrase boundaries lie.

As to the second possible reason, in the case at hand, this would mean that for each utterance there are (at least) two alternative ways of phonological phrasing, one syntactic and the other rhythmic. Circumstances like speaking style, speech tempo, or the way ELocuTio relates to INVENTIO and DISPOSITIO (e.g. prepared vs. spontaneous, careful vs. casual delivery) might favour either the one or the other, however different from one another. This is indeed how one of the main architects of the rhythmic theory, Eduard Sievers, saw it:

Es verdient übrigens noch bemerkt zu werden, dass abgesehen von logisch oder rhetorisch besonders pointierter Sprechweise, wie sie namentlich dem gelehrten und schulmässigen Vortrage eigen ist, die rhythmische Gliederung des Satzes mächtiger zu sein pflegt als die etymologisch-logische nach Worten und grammatisch zusammengehörigen Wortgruppen. ${ }^{14}$ (Sievers 1901b: 288)

This kind of conclusion would seem to find support in the experimental literature, where there are hints that factors such as speech rate play a role in favouring a syntactic or an antisyntactic phonological grouping. For example, for Mandarin Chinese the two possible phrasings in (17) have been found, established on tonal evidence (Cheng 1973, etc.):

(17) a. slow speech:

(Old Li) (buys) (good wine)

R L L $\quad$ R L

\footnotetext{
${ }^{12}$ Even when the phrasing is rhythmic rather than syntactic, with weak constituents left- rather than rightassociated, there must be some morphosyntactic forward planning prior to ELOCUTIO, at least up to the following word within the same syntactic phrase, to account for such phenomena as the shape alternation of the indefinite article, $a-$ an, which is sensitive to the onset of that word:

(i) (Drink an) (urn a) (tea a) (day •)

${ }^{13}$ It is only in very fast speech that resyllabification and no glottal stop are sometimes possible. Glottal stop insertion or glottalisation themselves are often implicated in phonological phrasing, used to mark the beginning of a unit - more typically a phonological phrase than a phonological word, though.

${ }^{14}$ Translation: 'By the way, it deserves to be noted that the rhythmic grouping of the sentence is usually more potent than the etymological-logical one which groups in terms of words and grammatical phrases - disregarding a markedly logical or rhetorical way of speaking in the characteristic manner of learned and bookish delivery.'

Like in so much else, Luick (1923: 51-3) agreed with Sievers as to the flexibility of phonological phrasing, where rhythmic phrasing was considered the default in ordinary conversational speech. Steele (1775), too, was aware of (and indeed experimented with) variations of cadence-grouping in elocution; but the variants he envisaged were comparatively minor: e.g. (Every) (sentence in) (our) (language) vs. (Every) (sentence) (in our) (language), as in (10).
} 
b. faster:

$\begin{array}{cccc}\text { (Old Li buys) } & \text { (good wine) } \\ \text { R R L } & \text { R L L }\end{array}$

Lexically each word has a Low tone (L), and there is a tone rule turning a Low into a Rising tone $(\mathrm{R})$ when followed by $\mathrm{L}$ in the same constituent - which shows that the verb, a phonological unit of its own in slow speech, is phrased with the subject in fast speech as one phonological phrase. Also, to account for contradictory experimental results, interindividual variation has sometimes been appealed to.

On the whole, the influence of speech tempo and other circumstances of the planning and execution of utterances has not been systematically studied. Nor is it well understood how an experimental set-up can influence the outcome of a phrasing experiment. In most of the experiments that purport to demonstrate isomorphic phonological-syntactic phrasing à la Selkirk and Nespor \& Vogel, the task of the subjects was to memorise sentences presented to them in standard English orthography and then to reproduce them orally. This is hardly reflective of the most natural way of thinking and speaking, and hence phrasing.

What is important to observe is whether differences in phrasing depending on speech rate or style are a matter of eliminating boundaries between adjacent phonological units or of systematically shifting boundaries. The former is the case in the Mandarin Chinese example (17) and similarly elsewhere. The latter would be the case when iambic (4a) is rephrased as trochaic (4b) in English. The relevant difference in Germanic would thus be qualitative rather than quantitative, with two wholly different modes of phonological phrasing available when thoughts are pronounced.

\subsubsection{Tell-tale history}

The tension between phonological phrasings differing in such a principled manner in Germanic certainly needs further study, and we will review some work on real-time planning and phrasing in section 4. But before this, in section 2 - accompanied by a theoretical reconsideration (section 3) - we take an indirect approach: examining historical developments in Germanic having to do with cliticisation and the creation of inflectional morphology, we ask by what sort of phonological phrasing they could have been enabled or encouraged. That is, we seek to identify the kind of phonological phrasing that was so salient as over time to have shaped words and the ways - morphosyntactic and phonological - of their construction. Whatever the synchronic possibilities at any given time, the storyline is that subsequent changes were all or overwhelmingly of one kind, consistent with only one of the options.

\section{THE JUDGEMENT OF HISTORY}

\subsection{From enclitics to inflectional suffixes and suffix accretions: phonological phrasing along with the syntax}

Virtually all of Germanic inflection is suffixal rather than prefixal, and there are a number of attested or plausibly reconstructed cases where inflectional suffixes, or phonologically bound forms on the way to becoming morphologically bound, have been created from enclitics through 'univerbation'. This suggests that when they were clitics, they were enclitics rather than proclitics, which implies a trochaic/dactylic rather than an iambic/anapaestic phonological phrasing. When this sort of development occurred, the syntax itself was often trochaic, contrary to what is the norm for basic constructions in today's Germanic: [Lex Gram], with the Gram word destined for clitic-hood and eventually affix-hood following its Lex word. 
Their phrasing as phonological and ultimately morphological co-constituents could therefore only seem natural, if univerbation were to take place. However, as we will see presently (section 2.2), iambic syntax, $\left[\mathrm{Gram}_{1} \mathrm{Lex}_{1}\right]\left[\mathrm{Gram}_{2} \mathrm{Lex}_{2}\right]$, has been equally conducive to encliticisation and inflectional suffixation in Germanic, with the phonological phrasing counter-syntactic, $\left(\operatorname{Lex}_{1} \mathrm{Gram}_{2}\right)$. Also, with word order in early Germanic none too rigid, there was often the alternative of $\left[\mathrm{Lex}_{1} \mathrm{Gram}_{1}\right]\left[\mathrm{Lex}_{2} \mathrm{Gram}_{2}\right]$ syntax especially where verbs were involved in phrasal construction; but significantly, no procliticisations $\left(\mathrm{Gram}_{1} \operatorname{Lex}_{2}\right)$ and prefixations $\mathrm{Gram}_{1}$-Lex 2 were initiated here.

\subsubsection{Dental preterite}

One relevant case is the dental suffix for the preterite tense of weak verbs, whose source (or at any rate the source reconstructed most plausibly) was the auxiliary or light verb 'to do, make', Proto-Germanic *ded- in the imperfect form (from Proto-Indo-European *dhe-dhe $H_{1^{-}}$, with reduplicating present). The appropriately inflected form of 'do' was periphrastically combined with such verbs - many noun-, adjective-, or verb-derived by means of suffix - $j$, causing umlaut and gemination - which on formal grounds could not participate in the ablaut patterns of stem vowels, which was the regular mode of tense marking. Many different views have been advanced about the precise verbal form that 'do'was combined with (the verb root or some adjectivalised or nominalised form, probably the resultative participle, itself with dental suffix; thus: causative-resultative 'he made painted' > plain past tense 'he paint-ed') as well as about some inflectional forms at and after univerbation. In our view (as set out in Lahiri 2000), four stages need to be distinguished in the development from a syntactic to a morphological construction via encliticisation:

(18) Dental suffix of preterite of weak verbs < V=AUX 'do':

Stage I ((ROOT-/j/ TRANS INF $\left.)_{\omega}(\text { do-TNS.MOOD.PRS.NMB })_{\omega}\right)_{\Phi}$

Stage II $\left(\left(\text { ROOT }-/ \mathrm{j} / \text { TRANS }_{\omega}\right)_{\omega}=d o \text {-TNS.MOOD.PRS.NMB }\right)_{\omega}$

Stage III ((ROOT-/j/ TRANS $\left.^{-} d\right)$-TNS.MOOD.PRS.NMB $)_{\omega}$

Stage IV (ROOT- $d$-TNS.MOOD.PRS.NMB) $)_{\omega}$

What matters for present purposes is that a new pan-Germanic suffix (now regularly /d/ in English and Dutch and / $\mathrm{t}$ / in German) developed from an enclitic, with the shape changes of the ancestral form plausibly accounted for under a phonological phrasing (Lex Gram), in this case mirroring the syntactic phrasing [Lex Gram]. However, [Lex Gram] was not the only ordering in early Germanic when Lex was a verb and Gram an auxiliary or light verb: but significantly, it was [Lex Gram], and not [Gram Lex], where the auxiliary managed to get univerbated with its verb.

\subsubsection{North Germanic middles and passives}

An analogous case, limited to North Germanic, is the creation of a middle and/or passive suffix from the reflexive pronoun. ${ }^{15}$ The ancestral form of the reflexive in Old Norse was sik (accusative singular); when encliticised it appeared as $=s k,=z k,=k$, and later $=s,=z$ as well as $=z t,=z s t$, and eventually became a suffix $-s t$ (Icelandic, Faroese) or $-s$ (Norwegian, Danish, Swedish), causing certain simplifications of final consonants of the inflections of verbs to which it was appended (e.g. Swedish active kall-a-r 'call', a-conjugation, finite, present - kall-

\footnotetext{
${ }^{15}$ And when the cases we adduce for our one-plot story are familiar from grammars and handbooks and uncontroversial in the particulars that matter for our storyline, extra referencing is superfluous.
} 
$a$-s, corresponding passive; Icelandic kall-ið call-2PL.ACT - kall-ist, corresponding middle). The syntactic phrasing was [VERB REFL], phonologically phrased as (VERB REFL), with the Gram word encliticised and then turned into a suffix. Or at any rate this was the syntax which permitted this chain of change events: with the verb able to occur in several positions in Old Norse, in particular final (which means following the reflexive) and second (preceding the reflexive), it is instructive to note again that only [Lex Gram], but not [Gram Lex], was to enable cliticisation (en-) and affixation (suf-).

\subsubsection{Icelandic $2 S G$ imperative}

Even more language-specifically and indeed register-specifically, Icelandic innovated a verbal inflection for $2 \mathrm{sG}$ in the imperative of informal speech, $-\partial u /-d u /-t u$, which is a reduced form of the 2sG nominative of the personal pronoun $p u$. The story is the same: the syntactic phrasing [Lex Gram], with the verb as the lexical partner in initial position in the imperative, is phonologically phrased as (Lex Gram), with the reflexive as the Gram word here encliticised and eventually a suffix, undergoing reductive and cluster-simplifying vocalic and consonantal shape changes consistent with being enclitic.

\subsubsection{Accretion of $2 S G$ indicative present, twice}

In a variation on this theme, a suffix was not newly created, but was merely added segmental substance to, which originated from an enclitic: the verbal suffix for 2 sG present indicative active in Proto-Germanic was -es/-is, but in Old English and Old High German it acquired a final / $/$. The source of this accretion was the onset of the $2 \mathrm{sG}$ nominative singular personal pronoun, $p u$ :

(19) Accretion of verbal inflection for $2 \mathrm{SG}$

$-e s t_{2 \mathrm{sG}}<-e s=t<-e s=p u \quad \mathrm{VERB}-2 \mathrm{sG}=\mathrm{PRO}_{\mathrm{Sbj}} \cdot 2 \mathrm{sG}$

The order that this development implies is [VERB PRO $\left._{S b j}\right]$, with subject after the verb: though rather a marked arrangement vis-à-vis SOV (verb-final) and SVO (finite-verb-second), this was the required inversion in yes/no interrogatives, which is a context where, as the addressees of a question, 2nd person pronouns, the targets of the encliticisation, are most prone to appear as subjects. It should be noted that neither in VS interrogatives nor in marked OVS or XVS declaratives are verb and subject pronoun syntactic co-constituents at a hierarchical level low enough to license the inclusion in one phonological word.

\subsubsection{Gram - Gram}

A very common configuration leading to clitic clustering in early Germanic was the succession of two grammatical elements, with the order between them typically rather rigid; and in some cases this eventually also yielded suffixes. Typically, the status and shape alternations attendant on prosodic subordination here would be affecting the second element more than the first, attesting to some kind of trochaic asymmetry. ${ }^{16}$

One example - if personal pronouns are taken to be grammatical rather than lexical even when strong rather than clitic - are the dual forms of 1st and 2nd person personal pronouns in the nominative, such as Old English, Old Saxon wit, git, Old Norse vit, it, Gothic wit, jut, which - like in many other languages with duals - derive from the plural stem plus the

\footnotetext{
${ }^{16}$ Although there is some variability here; cf. English 'tis $>$ it's.
} 
numeral 'two', *we=dwo, with the numeral reduced via /du/ to a bare dental, a shape change not unnatural at the end of a clitic group.

Much more recently, auxiliaries in English began to distinguish themselves from lexical verbs among other things in negation; and the reduced vowel-less form $n$ 't of negative not has been suggested (Zwicky \& Pullum 1983) to have the properties of a suffix rather than an enclitic. English auxiliaries would thus have come to inflect for negation, sometimes regularly, with the stem of the auxiliary fully intact (is-nt, was-nt, have-nt, does-nt, would-nt, etc.), sometimes less regularly, with the auxiliary's stem also altered (ai-nt, wo-nt, do-nt, sha-nt) or showing a paradigmatic gap (*may-nt).

As in other Indo-European languages, when the original Germanic negative particle ne/ni was in syntactic construction with a following auxiliary verb or a pronoun or quantifier with an initial vowel or initial $/ \mathrm{h}$, w/, ne/ni could - with various degrees of productivity in languages such as Old Frisian, Old/Middle English, Old/Middle High German, Old Saxon, Gothic, or Old Norse - phonologically associate in the direction dictated by syntax: to the right. The negative particle would lose its vowel, and its partners had to lack an onset underlyingly or would have to be able to shed it, as was the case with initial $/ \mathrm{h}$, w/. To illustrate from Old English: $n=i$ is $\mathrm{NEG}=\mathrm{is}, n=$ ef fre $\mathrm{NEG}=\mathrm{ever}, n=\bar{a}$ wiht $\mathrm{NEG}=\mathrm{thing}$ ( $>$ $n \bar{a} h t, n \bar{a} u h t$ 'not'), $n=$ abban $\mathrm{NEG}=$ have (habban), $n=y$ llan $\mathrm{NEG}=$ will (willan). Such negative contractions have been referred to as procliticisation; but there is no marked asymmetry between weak and strong here, since the second constituent - always unstressed in this close kind of construction ${ }^{17}$ - is also incurring segmental loss, and such constructions should therefore more neutrally be considered clitic clusters. Significantly, in contradistinction to reduced negative n't after auxiliaries in later English, reduced negative $n$ before auxiliaries and pronouns/quantifiers would not turn into productive inflection in any relevant Germanic language: negative contraction was to be discontinued, with only a few lexical opposites such as English never - ever, none - one, nor - or, neither - either surviving.

Procliticisation, if this is what it was, was not a route to morphological success in Germanic.

\subsection{From enclitics to inflectional suffixes: phonological phrasing against the syntax}

The history of other inflectional suffixes in Germanic is ostensibly similar, involving univerbation - except that the ancestral words of these suffixes were not syntactic coconstituents of the words thus to gain inflections via encliticisation. It is these developments which most conspicuously point to a phonological phrasing at odds with syntactic constituency.

\subsubsection{Inflecting prepositions}

Close combinations of prepositions with either personal pronouns or definite articles are crosslinguistically widespread. ${ }^{18}$ The latter are of special interest here because determiners are not, in any framework, analysable as surface-syntactic co-constituents of prepositions: they go with nouns or noun phrases in the syntax. German is among the languages where many prepositions (though not all) tightly combine with following definite articles (though not in all forms). Such instances as in (20a), found in even the most formal of styles and written without apostrophe or other mark of separation, are usually analysed as encliticisation, where the prosodically subordinated enclitic definite article loses much of its segmental substance, with

\footnotetext{
${ }^{17}$ To judge from specialist studies such as Levin (1958), Blockley (1988; 1990), Jack (1999) for Old English.

${ }^{18}$ Interestingly, the same cannot be said of postpositions.
} 
only the final consonant remaining (sometimes, namely in im, assimilating to the preposition's final consonant); ${ }^{19}$ in colloquial speech such preposition-article contractions are more productive, affecting more prepositions and more article forms (20b):

(20) PREP [DEF N], (PREP=DEF) N

a. in d-as $N$, zu d-er $N$, in d-em $N>$ in $=s, z u=r$, im $(i n=m) N$ into the $\mathrm{N}$, to the $\mathrm{N}$, in the-M.SG.DAT $\mathrm{N}$

b. unter $d$-as $N$, in $d$-ie $N$, mit $d$-em $N>$ unter $=s N$, in $=n e N$, mip $=m N$ under the $\mathrm{N}$, in the-PL/FEM.SG.ACC $\mathrm{N}$, with the $\mathrm{N}$

Diachronically speaking, this means the definite article in its new enclitic forms has lost the very part which was marking definiteness of old: the initial dental. For some dialects, such as Ruhrdeutsch, it has been argued that these combinations have become genuinely morphological, with the relics of the definite article now suffixes and forming a paradigmatic system of their own, no longer regularly derivable from the full articles by mere phonological reduction - e.g. im vis-à-vis uncontracted in den and in das (Nübling 1992; Schiering 2005; Kabak \& Schiering 2006).

\subsubsection{German and Dutch agreeing complementisers}

A second case where syntactic boundaries have not been obstacles to joint phonological phrasing are complementisers inflected for the subject's person and number in German, Dutch, and Frisian dialects - as shown in (21) for Middle Bavarian, with the conditional complementiser and with gaps for 3SG and 3PL:

(21) a. wenn- $\varnothing$ i kimm- $\varnothing$

when-1sG I come-1sG

b. wenn-st (du) kimm-st

when-2sG (you) come-2sG

c. wenn-ma (mia) kemm-a(n) (realised as wemma)

when-1PL (we) come-1PL

d. wenn-ts (es) kemm-ts

when-2PL (you) come-2PL

'when I/you/we/you come'

With more complex cases of complementation, with the general-purpose complementiser dass 'that' overtly suppressed, words other than complementisers themselves may find themselves as hosts of person and number marking in addition to verbal inflection:

(22) je öfter $[$ dass $]=$ st kimm-st ...

the more often $[$ that $]=2 \mathrm{sG}$ come- $2 \mathrm{SG} \ldots$

'the more often you come ...'

Beginning in the Middle Ages, a first stage in this line of development, occurring independently in the relevant varieties of German, Dutch and Frisian, was the encliticisation of subject personal pronouns to the finite verb and their extension from there to complementisers - not syntactic co-constituents. Subsequently, actual inflectional endings

\footnotetext{
${ }^{19}$ Though it should be noted that there tends to be a semantic contrast between contracted and separated forms: specific reference of noun phrases militates against contraction.
} 
of the verbs themselves could be transferred to complementisers, supplanting the enclitic pronouns in $1 \mathrm{sG}, 2 \mathrm{SG}$ and $2 \mathrm{PL}$ in Bavarian. ${ }^{20}$

\subsubsection{Bavarian interrogative inflection}

Modal or discourse particles are more popular in some languages than in others: in colloquial German they flourish, while in English they do not. Their occurrence is typically limited in terms of clause types: main rather than subordinate; either declarative, interrogative, imperative, or exclamative. They would seem to be clausal constituents; but, as is seen by comparison with the adverbs they often derive from (23), their positioning is typically rather limited, with finite verbs (in second position in main clauses) often, but not necessarily always, as their closest surface associates (24):

(23) a. Oma trinkt vielleicht/eben Tee.

'Granny probably/right now drinks tea.'

b. Vielleicht/eben trinkt Oma Tee. 'Probably/right now drinks Granny tea.'

c. Trinkt Oma vielleicht/eben Tee? 'Does Granny probably/right now drink tea?'

(24) a. Oma trinkt vielleicht/eben Tee.

'Granny drinks tea, and it is amazing how much of it/how fast she drinks it.'

'Granny drinks tea, and that can't be helped.'

b. *Vielleicht/eben trinkt Oma Tee.

c. *Trinkt Oma vielleicht/eben Tee? on the discourse particle reading

Prosodically, discourse particles are more attenuated than their adverbial counterparts and often ancestors vis-à-vis other clause parts, these being prone to the prosodic strengthening that comes with focus; and that they are encliticised (never procliticised!) is sometimes evident from formal reductions. In particular, denn - historically derived from an adverb 'and then' (in German continuingly distinct: dann) and a coordinative conjunction (denn 'because, for', with causal sense derived from temporal) - has a severely curtailed clitic form $=n$ as a discourse particle, in which function it is confined to interrogatives:

(25) a. Wo war-st=n du gestern? Wo war-st du=n gestern?

'Where, I'm asking you, were-2sG=n you/were-2sG you $=n$ yesterday?'

b. War-st=n du krank? War-st du=n krank?

'Were-2sG=n you/Were-2sG you=n perhaps ill?'

In Bavarian, developments have gone beyond encliticisation and $=n$ has become an obligatory part of wh-questions, morphologically bound to finite verbs. It has accordingly attained the status of a verbal inflection, analysed by Bayer (2010) as signalling agreement with a wh-phrase in main clauses.

\footnotetext{
${ }^{20}$ Or perhaps rather coalescing with them: wenn-st $=d d u$ kimm-st, wenn- $a(n)=$ ma mia kemm- $a(n)$, wenn-ts $=s$ es kemm-ts. Recent treatments of inflecting complementisers in West Germanic, showing a variety of patterns other than that here given for Bavarian, include Weiss (2005), De Vogelaer (2010), and De Vogelaer \& Van der Auwera (2010). The latter also examine person-number inflections of answering particles ('yes', 'no', 'valid'), which likewise involve encliticisation of personal pronouns and direct transference of verbal inflections.
} 


\subsubsection{North Germanic definiteness marking}

Definite articles, already touched on above (section 2.2.1) and to re-appear below (section 2.4.2), were a Germanic innovation, arriving on the familiar grammaticalisation path that departs from (distal) demonstratives. It is the postposed definite noun articles peculiar to North Germanic, illustrated from Swedish in (26) (marking definiteness plus number and gender), which have the worst record as regards the mismatching of phonological and morphosyntactic phrasing. ${ }^{21}$

\begin{tabular}{|c|c|c|c|}
\hline \multirow{2}{*}{ indefinite } & \multicolumn{2}{|r|}{ 'large bear' } & \multirow[b]{2}{*}{ en stor björn } \\
\hline & SG & en björn & \\
\hline & PL & björn-ar & stor-a björn-ar \\
\hline & SG & björn $=e n$ & den stor- $a$ björn $=e n$ \\
\hline & PL & björn-ar $=n a$ & de stor- $a$ björn-ar $=n a$ \\
\hline
\end{tabular}

There is much that is still controversial about the early development of the definite noun articles in the Scandinavian Germanic languages, concerning the timing (with a starting point some time between 500 and $1100 \mathrm{CE}$ ), the precise ancestral forms, and the source construction(s). For present purposes, the two source constructions that have been contemplated are equally relevant, because they are equally offensive: in neither case is it the noun itself that the definite article is originally associated with. One, favoured by Jacob Grimm (1837) and many others, is an attributive construction with perhaps an appositional flavour which has an adjective in postnominal position (27a; hypothetical example); the other has proper names as heads, again with a following adjective as an appositional epithet (27b) with the demonstrative-derived pristine definite article as a syntactic co-constituent not of the noun (or proper name), but of the appositum, an adjective in the weak declension, which is the original Germanic marker of definiteness and also the form for nominalisations. ${ }^{22}$
a. björnr [(h)inn stori]
'bear, the large (one)'
b. Björnr [(h)inn harfagri]
'Björn, the fair-haired (one)'

This new definiteness marker in complex noun phrases then came to be associated with the head noun, with phonological phrasing as the agent (or perhaps concomitant) of change:

$$
\mathrm{N}[\mathrm{DEF} A],(\mathrm{N} \text { DEF }) \mathrm{A}>\mathrm{N}=\mathrm{DEF} \ldots
$$

Attributive adjectives themselves would switch to prenominal position, requiring a definite article of their own (again demonstrative-derived, though now from pann rather than $(h)$ inn as of old). The noun's definiteness marker essentially remained an enclitic in insular Scandinavian Germanic, continuing to itself inflect for case (e.g. Icelandic bjarn-ar=in-s bearGEN.SG=DEF.M.SG-GEN.SG). In the continental languages its distributional pattern has become that of a suffix (e.g. Swedish björn-en-s bear-DEF.M.SG-GEN.SG), although the noun's definite

\footnotetext{
${ }^{21}$ Equally routine was the Germanic grammaticalisation of indefinite articles from the numeral 'one'. While other phrasing mismatchings (to be outlined presently) generalise to both definite and indefinite articles, the Scandinavian definite pattern is without indefinite analogue.

${ }^{22}$ See Plank (2003) on the possibly subtle transition from complex to simple syntactic phrasehood with such postnominal modifiers, also reflected in the intonation.
} 
marker continues to remain outside the domain for assigning tonal accents to disyllabic words, as behoves an enclitic (Lahiri et al. 2005; 2006).

\subsection{Ways of losing an inflectional prefix}

The only inflectional prefix in Germanic - originally so loosely attached as to permit internal clitics (as in Gothic $g a=u=l a u b j a-t s$ PERFECTIVE=INTERROGATIVE-believe-2DUAL), and therefore perhaps itself having the status of a proclitic - is verbal $g a-/ g e-/ g i$ - for perfective/resultative aspect and participle, and this inherited nonesuch was often dropped. Being an unstressed prefix at the stage of these developments in West Germanic, it was vulnerable to effacement; but there were differences as to how precisely it disappeared - as sketched in (29) (after Paul 1916-20, vol. 2: 276-9).

(29) Loss of verbal prefix ge- through phonological effacement

a. involving palatalisation and loss of glide and vowel, as in English: $g e-\mathrm{STEM}>j e-\mathrm{STEM}>i$-STEM $>$ STEM

b. involving complete assimilation of obstruent, as in Bavarian and other Upper German: $g e$-STEM $>g$-STEM $>g / \varnothing$-STEM

c. involving loss of onset consonant and final vowel, but only after encliticisation, as in Low German:

$$
\mathrm{X} g e-\mathrm{STEM}>\mathrm{X}=\text { ge } \mathrm{STEM}>\mathrm{X}=\text { ○ } \mathrm{STEM}>\mathrm{X} \text { STEM }
$$

Most instructively in the present context, Low German would phonologically phrase the verb's prefix with preceding material of any kind, from the last prominent syllable onward. That is, an unstressed morphological word part became detached and was encliticised across word or syntactic phrase boundaries - before, landed in an even more exposed position, it fell victim to phonological erosion.

\subsection{Encliticisation preference, and ensuing shape changes of clitics}

It was not all that often that clitics (en-) made it to inflectional affixes (suf-) during the two and a half millennia or so of common or separate Germanic. As shown in the preceding survey, such enclitics-to-become-suffixes could themselves come about through phonological phrasing within or equally across the boundaries of syntactic phrases. Invariably, the configuration enabling cliticisation was one where the lexical word to host a clitic came before the grammatical word to be subordinated as a clitic; where word order in syntactic constructions was variable, grammatical-before-lexical word was not an environment conducive to procliticisation.

This same sort of asymmetry is encountered again and again in cliticisation developments in Germanic when phonological binding was not to lead to morphological binding, however tenuous the dividing line. Here is a list of pertinent observations for English and German, with particular reference to sandhi-type shape changes in clitic constructions; and it could easily be extended for these Germanic languages and the others.

\subsubsection{A miscellany of encliticisations}

2.4.1.1. The English infinitival complementiser to, historically deriving from an allativepurposive preposition, changed to $=t$, with both onset $/ \mathrm{t} / \mathrm{of}$ COMP and coda consonants of 
the host undergoing further assimilatory changes when to, a syntactic co-constituent of the non-finite verb, is encliticised to an auxiliary or governing verb on the way to auxiliarisation:

$\operatorname{ough}(t)=t a, h a f=t a, g o n=n a, w a n=n a, \operatorname{spos}(t)=t a$, plan $=t a$, etc.

2.4.1.2. The English modal auxiliaries will, would, finite am/is/are, finite have/had $>=l l,=d$, $=m /=s /=r,=v /=d$, shedding onset consonants and dropping their vowels when encliticised, across a syntactic boundary, to the subject. Non-finite have $>=\partial v$, within a syntactic phrase (should =av come).

2.4.1.3. The English preposition of $>=0$, encliticising to the head noun, rather than procliticising to its own complement noun phrase (pint=a milk, * pint $a=$ milk).

2.4.1.4. Coordinative conjunctions, which symmetrically join two conjuncts semantically, morphosyntactically phrase with the following conjunct in Germanic languages, in line with their historical sources (and/und 'thereupon', Scandinavian og/och 'add to this'); but they have come to phonologically phrase with preceding conjuncts, at least in fluent colloquial speech:

$$
\begin{array}{ll}
\text { semantic grouping: } & \&<\text { fish, chips }> \\
\text { syntactic grouping: } & \text { [fish] [and [chips]] } \\
\text { phonological phrasing: } & (\text { fish }=\text { n) }(\text { chips })
\end{array}
$$

If and were a proclitic, the attendant formal changes like the loss of its vowel and final consonant, assimilation of the surviving nasal to the left-hand rather than to the right-hand conjunct (*bread $m$ butter, *up $n$ down) would be implausible.

2.4.1.5. Discourse/modal particles in colloquial German, whatever their historical sources and their syntactic associations, lean left, and sometimes manifestly encliticise (denn > ' $n$ : see above, section 2.2.3).

2.4.1.6. To the extent that the possessive pronoun was implicated in the creation of the English $s$ genitive, a syntactic co-constituent of the following possessum noun would have been re-attached, as an enclitic, to the preceding possessor noun:

(32) John [(h)is hat] > (John is) hat

2.4.1.7. The nominative, i.e. subject form of 1 pL personal pronouns has often acquired a labial onset instead of etymological w-/v-: e.g. Middle High German, Bavarian, Yiddish mir, Dutch me, Norwegian mer (e.g. Howe 1996; De Vogelaer 2010). This shape change occurred when subject pronouns were cliticised to a person-number-agreeing 1PL verb in -en when following it, with the assimilation $V E R B-e n=v / w>V E R B-e n /-e m=m$ then generalised to independent uses (kommen=mir, mir kommen 'we come'). Finite verb and encliticised subject pronoun are not syntactic co-constituents.

Similarly, the 2SG pronouns jij (strong form) and je (weak) in Dutch derive from a 2PL pronoun $g h i$ : the shape change through palatalisation $(=d j i /=d j e)$ and further reduction $(=d i /=d e)$ came about when the pronoun was enclitic to the verb (De Vogelaer 2010: 17). 
2.4.1.8. Subject and object personal pronouns could appear in different positions in the clause, with only the finite verb in second position in main clauses a fixed positional pivot in all of older Germanic (itself arguably due to encliticisation, with verbs prosodically light in Germanic, hence gravitating towards the Wackernagel position). Whether and precisely when personal pronouns were clitic or only 'weak' as opposed to 'heavy' is a continuing matter of scholarly debate. ${ }^{23}$ Whenever distinctly clitic forms of personal pronouns were to emerge in the daughter languages, there was a clear tendency for them to be phonologically phrased with preceding material, such as verbs or complementisers - and syntactic co-constituency could hardly have mattered less. ${ }^{24}$ Bavarian, typical of regional colloquial varieties of German, illustrates this general preference for encliticisation:

\begin{tabular}{|c|c|c|}
\hline fully non-clitic & Er gibt es mir & lit. 'he gives it (ACC) me (DAT)' \\
\hline Obj pronouns clitic & $E r / * p=g i b t=m p=s$ & 'he gives me it' \\
\hline & $E r / * p=g i b t=s=m p$ & 'he gives it me' \\
\hline Sbj pronoun also clitic & $G i b t=p=s=m p ?$ & yes/no interrogative, verb-initial \\
\hline ncliticised to COMP & $\begin{array}{l}\text { Gibt }=p=m p=s ? \\
\text { wenn }=p=m p=s \text { gibt } \\
\text { wenn }=p=s=m p \text { gibt }\end{array}$ & $\begin{array}{l}\text { 'if he gives me it' } \\
\text { 'if he gives it me' }\end{array}$ \\
\hline
\end{tabular}

One apparent exception in German is the 3SG neuter pronoun es, clitic form $s$, which does procliticise to the following verb - but only when it is an expletive (34a), while it again follows the general asymmetric pattern when it is referential (34b):
a. $E s / s=$ regnet Regnet es/ $=s$ ?
'it rains' yes/no interrogative, verb-initial
b. das Kind ... es $/{ }^{*} s=$ betet 'the child (NEUT) ... it prays' Betet es $=s$ ? yes/no interrogative, verb-initial

\subsubsection{The definite article conundrum}

Definite articles in West Germanic, of the shape $\mathrm{CV}(\mathrm{C})$, with initial dental as the surviving segment of the original demonstrative from which the definite article was grammaticalised, are somewhat ambivalent in their phrasing behaviour, and would therefore deserve special indepth study. Syntactically they are part of their noun (or determiner) phrases; phonologically they often - or indeed as a default - phrase with whatever strong material precedes them, disregarding syntactic constituency.

2.4.2.1. Modern Dutch is a case in point: at the juncture between the verb and the definite article of the following object noun phrase, voicing assimilations occur whose domain is

\footnotetext{
${ }^{23}$ See Koopman (1997) for a sober review of Old English, countering the (continuing) clitic exuberance in some of the generative literature.

${ }^{24}$ For Old English it has sometimes been claimed that personal pronouns could be proclitic to finite verbs in main clauses, or else the finite verb would not appear in second position. Crucial examples are like this:

pin agen geleafa pe hafo gehaledne.

'Thine own faith thee has healed.'

It is debatable, however, whether the pronouns are clitic here and whether they phonologically associate with the verb to their right: leftward association with whatever prosodically strong constituent precedes them, as argued for here, would equally satisfy the finite-verb-second requirement.

For Old High German, the careful single-text study of Somers Wicka (2009) leaves no doubt about the massive, even exclusive predominance of encliticisation.
} 
limited to phonological words (as demonstrated in Lahiri, Jongman, \& Sereno 1990, and as earlier observed in Sweet 1877; cf. also Berendsen 1986; Gussenhoven 1986); the same holds for the clitic form də.r of feminine $3 \mathrm{SG}$ possessive haar:

(35) a. Ik [zoek [de krant]] ik (zoek de) (krant)

b. Ik [zoek [der krant]] ik (zoek der) (krant)

'I am looking for the/her newspaper.'

In principle, three options would be available for phonological phrasing and the attendant junctural adjustments: progressive assimilation where the two adjacent items observe the same constraints against internal voiced clusters as a single lexical item (36a); or regressive voicing assimilation as in a compound (36b); or - and this is the only option that is actually ruled out - no assimilation as across a boundary (36c).

(36) a. ik (zoe[k] $[\mathrm{t}] \mathrm{e})_{\omega}(\mathrm{krant})_{\omega}$ progressive assimilation of article

b. ik $\left((\mathrm{zoe}[\mathrm{g}])_{\omega}[\mathrm{d}] \mathrm{e}\right)_{\omega}(\mathrm{krant})_{\omega}$

c. $*$ ik $(\text { zoe }[\mathrm{k}])_{\omega}([\mathrm{d}] \mathrm{e} \text { krant })_{\omega}$ regressive assimilation of verb no assimilation

The point to note is that de must share the voicing of the preceding word, either voiced or voiceless, as elsewhere in encliticisation in Dutch (e.g. ik zoek=der 'I look for her': zoe[g][d]er, zoe $[\mathrm{k}][\mathrm{t}] \mathrm{er},{ }^{*} \mathrm{zoe}[\mathrm{k}][\mathrm{d}] \mathrm{er}$, where der is again the clitic form of feminine 3sG haar 'her', with the object and possessive forms identical).

\subsubsection{Colloquial Standard German is like Dutch:}

(37) [frag [den Peter]] (FRAgy) (PE ter) 'Ask Peter!'

Rightward assimilation to the labial in this kind of example - *(FRAG) (mPE.ter) - is only permissible at a speech rate/style where nasal assimilation occurs across phonological word boundaries anyhow.

For Austrian German, Luick (1923: 49) gives these anti-syntactic phrasings without further ado, with the object pronoun in the strong (38a) and an enclitic form (38b):

(38) [Gib [mir] [das Buch]]

a. $g \overline{1} b$ mias $b \bar{u} \chi$

b. gib mas bū

'Give me the book!'

2.4.2.3. In contemporary Upper High German, comprising Bavarian and Alemannic, the definite article is reduced even in none-too-informal speech (as in (38)) - though with an anaphoric (=syllabic) and a unique-reference (=non-syllabic) definite article distinguished in Bavarian, and with the syllabic form required before an adjective in Swiss Alemannic. 
Definite article in Upper German

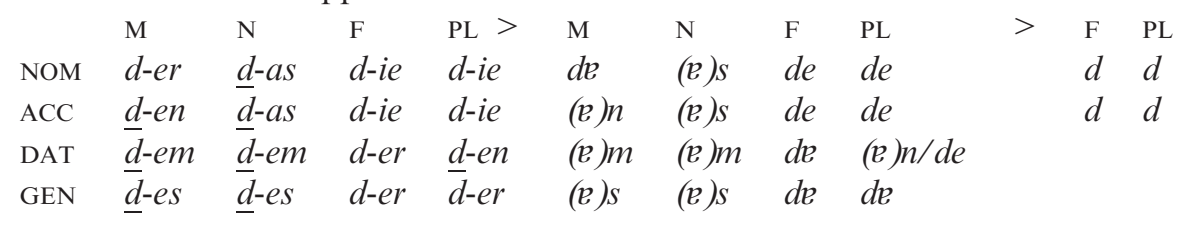

The reductive changes involved are as follows: (i) delete the first consonant (/d/) if the syllable is closed; (ii) delete final / $/$. What sort of phonological phrasing of the definite article would naturally account for the sort of consonant-deletion pattern shown in (39)? Invariable right association, as the syntax would have it, would not. These are plausible reductions, on the other hand, when the definite article forms the end of a phonological word, irrespective of the onset of the following constituent.

One problem for our phrasing scenario here is that of the definite articles that are reduced so far as even lexically to lack a vowel, in particular $d$, corresponding to the Standard German full form die. (40) shows how $d$ DEF.ACC.SG.FEM/ACC.PL is actually realised in Bavarian (similarly in Alemannic) in combination with the different onsets of nouns, in noun phrases which are the direct objects of a preceding verb in the imperative. ${ }^{25}$ Since Bavarian has no voicing contrast in labial and dental stops, the dental $d$, when realised, is a voiceless [t].

\begin{tabular}{|c|c|c|c|c|c|}
\hline \multirow[t]{4}{*}{ a. } & $\mathrm{Hol}$ & $\varnothing$ & Decken! & 'Get the & blankets!' \\
\hline & & $\varnothing$ & Gans & & goose \\
\hline & & $\varnothing$ & Kissen & & cushions \\
\hline & & $\varnothing$ & Betten & & beds \\
\hline \multirow[t]{2}{*}{ b. } & $\mathrm{Hol}$ & $\varnothing$ & Pfannen [pf] & 'Get the & pans!' \\
\hline & & $\varnothing$ & Zither [ts] & & zither \\
\hline \multirow[t]{5}{*}{ c. } & $\mathrm{Hol}$ & [pf] & Federn [f] & 'Get the & feathers!' \\
\hline & & [ts] & Sachen [s] & & things \\
\hline & & {$\left[\mathrm{t} \int\right]$} & Schüssel []] & & bowl \\
\hline & & {$[\mathrm{tv}]$} & Wannen [v] & & vats \\
\hline & & [th] & Hosen [h] & & trousers \\
\hline \multirow[t]{4}{*}{ d. } & $\mathrm{Hol}$ & {$[\mathrm{tl}]$} & Leiter & 'Get the & ladder!' \\
\hline & & [tn] & Nägel & & nails \\
\hline & & [tr] & Reiter & & riders \\
\hline & & [pm] & Milch & & milk \\
\hline e. & $\mathrm{Hol}$ & [t?] & Ecken & 'Get the & corners!' \\
\hline
\end{tabular}

That is, before stops and affricates of all places of articulation, the plural and feminine singular accusative definite article, syncretic with nominative, has become inaudible (40a, b); ${ }^{26}$ before fricatives and sonorant consonants, its single coronal segment remains $(40 \mathrm{c}, \mathrm{d})$, getting assimilated to labials, and frequently yielding onset clusters impermissible at left word edges ([tv, th, tl, tn, pm]); before vowels (40e), the coronal segment remains too, inducing a glottal-

\footnotetext{
${ }^{25}$ For particulars on the form, distribution, and status of such Upper German definiteness markers see Krähenmann \& Plank (2004). Their take is that such non-syllabic definites have acquired more or less all trappings of prefixes.

${ }^{26}$ In varieties of Swiss German where the fortis/lenis contrast has become one of geminate/singleton (see Lahiri \& Krähenmann 2004 for the full diachronic scenario), a non-syllabic definite article induces gemination. In Bavarian, this contrast has been neutralised anyhow, except with single velars.
} 
stop-like onset not so prominent with vowel-initial words otherwise in Upper German and

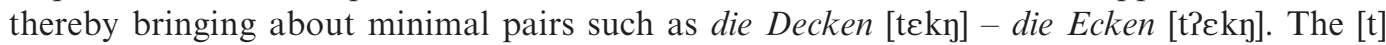
does not become a true onset, a situation which is identical to that of the unstressed prefixes, which do not resyllabify either: be?antwortet, mit?arbeiten. Such formal alternations would seem difficult to reconcile with a general preference for all grammatical words to phonologically associate leftwards. Still, without further study we do not want to rule out that even plain consonantal/t/ does lean left rather than right in such varieties of German (which could account for minimal pairs like that just mentioned). On the other hand, definite noun phrases are topics, and as such will frequently occur in sentence-initial position - with plainly nothing there to left-associate with. This is perhaps the most salient situation where the phonological phrasing default can be overruled, and procliticisation is getting its rare chance. $^{27}$

\section{Excursus: Selkirk's Proclitics AND REAdJusting to trochaic Grouping}

The historical developments in Germanic outlined above suggest that encliticisation is the default (though under particular circumstances sometimes blocked) and procliticisation is possible only if there is no host available to encliticise on to. However, as we mentioned earlier, the currently popular assumption is that there is necessarily a very close match between syntactic and phonological phrasing where the latter is assumed to be determined by surface morphosyntactic constituency.

Nespor \& Vogel assumed the following hierarchy: PROSODIC WORD > CLITIC GROUP > PHONOLOGICAL PHRASE > INTONATIONAL PHRASE $>$ UTTERANCE. Under their analysis, cliticisations would lead to the formation of a Clitic Group, and like Selkirk (1986) they also maintained the strict assumption that the phonological domains were non-recursive. The Clitic Group and the recursivity ban came under early attack, and most researchers assume that phonological encliticisation as well as compounding together result in recursive phonological word formation. ${ }^{28} \mathrm{~A}$ recursive phonological word analysis would allow for the phrasings in (41), irrespective of the direction of attachment of the reduced words.

(41) Phonological word formation without a Clitic Group

a. Tomorrow is a holiday

$(\text { tomorrow }=[\mathrm{z}]=\mathrm{a})_{\omega}(\text { holiday })_{\omega} \quad$ OR $(\text { tomorrow }=[\mathrm{z}])_{\omega}(\text { a holiday })_{\omega}$

b. White House parties can be long

$\left.\left((\text { white })_{\omega} \text { (house }\right)_{\omega}\right)_{\omega}$ (parties $)_{\omega}$ (can be $)_{\omega}(\text { long })_{\omega}$

c. John's white house is impractical

$\left(\right.$ John's $_{\omega}(\text { white })_{\omega}(\text { house }=\text { is })_{\omega}(\text { impractical })_{\omega} \quad$ OR $(\text { house })_{\omega}(\text { is }=\text { impractical })_{\omega}$

One of the issues of direct relevance here that are raised in Selkirk (1995/96) is the direction of attaching function words (Fnc) to neighbouring lexical words (Lex). She argues that a possible phrasing of [Fnc Lex] is such that the syntactic [XP] and phonological $(\mathrm{PPh})$ brackets/parentheses coincide owing to a general constraint on EDGE ALIGNMENT:

\footnotetext{
${ }^{27}$ The vowel-less definite article in Yorkshire English, $t(h)$, shows a similar associational pattern. The infinitival complementiser in Bavarian, vowel-less $z$ in competition with a full form zum/zun, would be another rare candidate for right-association; equally its Yorkshire English counterpart $t$.

${ }^{28}$ Vogel (2009) assumes a Composite Group to replace the Clitic Group, but in essence it has the same properties except that the former can also account for compounds.
} 
(42) Syntactic-phonological bracketing according to Selkirk (1995):

$\begin{array}{lllll}\text { S-structure: } & & {[\text { Fnc }} & \text { Lex }]_{X P} & \\ \text { P-structure: } & \text { (i) } & \left((\mathrm{fnc})_{\omega}\right. & \left.(\text { lex })_{\omega}\right)_{\varphi} & \text { Prosodic Word } \\ & \text { (ii) } & (\text { fnc } & \left.(\text { lex })_{\omega}\right)_{\varphi} & \text { Prosodic Clitic: free } \\ & \text { (iii) } & ((\text { fnc } & \left.\text { lex })_{\omega}\right)_{\varphi} & \text { Prosodic Clitic: internal } \\ & \text { (iv) } & ((\text { fnc }) & \left.\left.(\text { lex })_{\omega}\right)_{\omega}\right)_{\varphi} & \text { Prosodic Clitic: affixal }\end{array}$

Selkirk argues that in English, function words with weak forms are proclitics (underlined in the examples below), of the subtype 'free (pro-)clitics'. The structure and relevant examples are given in (43), where these proclitics are underlined.

(43) Selkirk: free proclitics

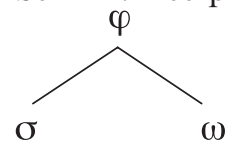

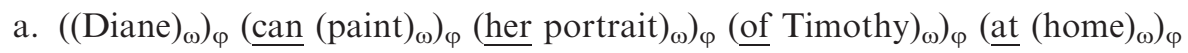

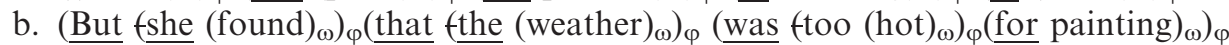

c. $\left(\underline{\text { She }}(\underline{\text { can }} \text { go })_{\varphi}\left(\text { to }(\text { Toronto })_{\omega}\right)_{\varphi}\left((\text { tomorrow })_{\omega}\right)_{\varphi}\right.$

Selkirk's evidence for the proclitic light syllable attaching directly to the phonological phrase $(\varphi)$, rather than to a prosodic word, is word-initial aspiration of voiceless stops (in stressed as well as unstressed syllables). This phonological process in English is assumed to be prosodicword-initial. Consequently, had the phonological domain of $(43 \mathrm{c})$ been (to Toronto) $)_{\omega}$, one would expect $* t^{h} o$ Toronto or $* t^{h} o T^{h}$ oronto, neither of which is allowed. The point to note is that in this instance Selkirk's analysis does not suggest encliticisation of to to the preceding phonological word, i.e. (she can $g o=t o$ ), which would inevitably block aspiration. Nevertheless, if we allow encliticisation due to leftwards attachment, the facts would be borne out. The preposition to cannot be aspirated, since it is cliticised to the preceding word.

(44) Alternative phrasing following trochaic grouping: $\omega$-initial aspiration

$(\text { She can })_{\omega}(\text { go to })_{\omega}(\text { Toronto })_{\omega}$ (tomorrow) $)_{\omega}$

[to] $\left[\mathrm{t}^{\mathrm{h}}\right] \quad\left[\mathrm{t}^{\mathrm{h}}\right]$

Noticeably, though, on the Selkirk (1995/96) approach enclitics are possible in English, whose hosts are preceding lexical words which the weak function words are not in syntactic construction with - which must really seem 'misfits' in this approach (e.g. [feed 'em], [see ya], etc. and compare (45) with (43)). These are of the subtype 'affixal (en-)clitics' as we see in (45).

(45) Selkirk: enclitics

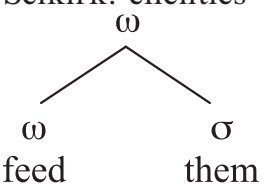

SYNTACTIC PHRASING

a. [Nina] [has left]

b. [Mary] [is coming]

c. [I] [will leave] too

d. [I] [would like] [to stay]
PHONOLOGICAL PHRASING

(Nina's) $)_{\omega}(\text { left })_{\omega}$

(Mary's) ${ }_{\omega}$ (coming)

$\left(I^{\prime} 11\right)_{\omega}(\text { leave })_{\omega}(\text { too })_{\omega}$

$\left(I^{\prime} d\right)_{\omega}(\text { like to })_{\omega}$ (stay) $)_{\omega}$ 
All of the examples in (45) fit with a trochaic phrasing analysis - weak function words by default encliticise to the preceding lexical word. In fact, will and would cliticise to the pronoun $I$ which could, in this instance, be a full prosodic word. Recall that a function word can encliticise to another function word quite easily, as we have seen in German: $z u m<z u$ dem, etc.

In sum, the approaches of both Selkirk and Nespor \& Vogel and all recent phrasing literature referring to segmental or junctural rules governed by phonological domains have largely assumed a direct syntax-to-phonology mapping. This is remarkable in view of earlier assumptions and Germanic history as outlined above. However, as far as we can ascertain, the Germanic facts addressed in this literature can all be accounted for by trochaic phrasing leading to encliticisation. In the next section, we briefly recapitulate experimental evidence which shows that in Germanic, function words encliticised to a preceding prosodic word are treated as a single prosodic unit for the purposes of regular speech production planning.

\section{EXPERIMENTAL EVIDENCE FOR TROCHAIC PHRASING}

Phonological phrasing, whether it matches or mismatches morphosyntactic phrasing, needs to be accounted for in models of language production. Existing models, such as the production model of Levelt (1989), would seem rather too comfortable with phonological phrasing following morphosyntactic constituency, and somewhat too uncomfortable with, for instance, trochaic phonology coupled with iambic syntax. Levelt, too, however refers to prosodic words as the unit of planning rather than morphosyntactic words.

In a series of experiments, Wheeldon \& Lahiri (1997) compared the PRODUCTION TIME IN PLANNING in various types of sentence production. They compared the time taken to plan speaking in a question-answer DELAYED paradigm, where listeners had time to prepare the answer, with an IMMEDIATE answer paradigm, where listeners had to respond to the question without delay. Both planning strategies are used by native speakers in normal conversation: we sometimes take time before beginning to speaking, while on other occasions we respond almost without thinking. The research question was as follows: what is the unit of planning an utterance? Do speakers plan in morphosyntactic units or do they plan on the basis of prosodic units built on surface morphosyntactic units? To answer this question, the following sentence stimuli with different hypothesised phrasings were created. ${ }^{29}$

Prepared and immediate speech production

SYNTACTIC PHRASING \& GLOSS PHONOLOGICAL PHRASING
a. ik drink het water
[I] [[drink] [the water]]
b. ik drink water
[I] [[drink] [water]]
c. ik drink vers water
[I] [[drink] [fresh water]]
(ik drink het $)_{\omega}$ (water) $)_{\omega}$
(ik drink $)_{\omega}$ (water) $)_{\omega}$
(ik drink) $)_{\omega}(\text { vers })_{\omega}$ (water $)_{\omega}$

The critical comparison was between (a) and (c), which should both consist of two prosodic units for planning purposes. The prediction was that if the time to plan the utterance took the number of prosodic units into account, both (a) and (b) would take the same amount of time while (c) would be longer. However, when the speaker had no time to plan, then the size of the initial unit would matter. If trochaic grouping was the correct phrasing mechanism, then (a) would take longer. If, however, the grammatical word de procliticised to allow for the grouping (ik drink) $)_{\omega}$ (het water) $)_{\omega}$ then all three sentence types (a), (b), and (c) would have the same initial prosodic unit $i k d r i n k$, and therefore take the same amount of time.

\footnotetext{
${ }^{29}$ The set of function words in the six experiments in Wheeldon \& Lahiri (1997) included de, het, and te: e.g. ik drink de wijn 'I drink the wine', ik zoek het water 'I seek the water', ik eet te snel 'I eat too quickly'.
} 
The task was as follows. Speakers heard a question What do you drink?, which was immediately followed by the visual display of one of the three options: THE WATER, WATER, or FRESH WATER. In the delayed paradigm, the speakers waited for a beep (presented at variable intervals from $750 \mathrm{msec}$. to $1500 \mathrm{msec}$.), after which they were instructed to answer the question. In the immediate response paradigm, no time could be spared and speakers were instructed to begin to speak the moment they heard the question. The results are summarised in (47).

$\begin{array}{lllll}\text { Summary of results for production planning time } \\ \text { Latency of onset of speech } & \begin{array}{l}\text { Delayed } \\ (46 c)\end{array} & 3 \omega & (46 a) & \text { Immediate } \\ \text { LONG } & (46 a)=(46 b) & 2 \omega & (46 b)=(46 c) & \text { longest first } \omega \\ \text { SHORT } & \text { shorter first } \omega\end{array}$

In the delayed task speakers took exactly the same time to plan producing sentences (46a) and (46b). Although the acoustic duration of the sentences differed (het was an extra syllable), het water and water took the same time to plan. That is, the number of phonological words mattered in planning to begin speaking. Naturally (46c) took longer since there were three phonological words. Thus, het evidently did not count in the planning phase. The acoustic duration of all utterances was entirely predictable, reflecting the number of segments and syllables: $(46 c)>(46 a)>(46 b)$.

As de was clearly attached to one of the neighbouring lexical words, the next obvious question is: which word was its host? Was het encliticised to drink or procliticised to water? In the immediate production paradigm this issue was resolved. Sentence (46a) took the longest time for subjects to prepare to speak! That is, it was the SIZE OF THE FIRST PHONOLOGICAL WORD that counted in the production planning. Sentence (46a) had the longest initial phonological word (ik drink het) ( $_{\omega}$ and hence it took the longest time to plan. Thus, the cliticisation of the article must be leftwards rather than rightwards - i.e. not *(ik drink) (het water) - because otherwise sentence (46a) would have taken the same amount of time in the immediate production paradigm as (46b) and (46c). Again, the actual acoustic duration was as one would expect, (46c) being the longest.

The conclusion is clear. In speech production planning, the semantic concept and the syntactic structure had already been generated, but the units that mattered for the speakers to begin to speak were phonological constituents and not syntactic constituents. Furthermore, encliticisation of the determiner, which violates morphosyntactic structure, caused (46a) to have the longest initial prosodic word unit, which was reflected in the longest latency in the spontaneous utterances.

\section{Conclusion}

On the evidence that we surveyed above, phonological phrasing is massively independent of syntactic phrasing throughout the history of Germanic languages. Throughout this history, trochaic/dactylic phrasing and encliticisation prevails, from the weak regular past tense suffix in all the languages to more circumscribed definite article encliticisations in North Germanic. Sometimes, as with the dental suffix, the prosodic phrasing does not go against the morphosyntactic phrasing. But quite often, the phrasing which led to phonological change of weak forms and their hosts violates syntactic phrasing, as is the case with the definite article in North Germanic or the English auxiliaries.

Experimental results show that modern Dutch speakers use the phonological word and not the syntactic word in planning their production. This phonological word can also comprehend an enclitic function word attaching to the preceding lexical word across 
morphosyntactic constituent boundaries. Thus, the preference for trochaic/dactylic phonological phrasing does not seem to have changed very much over time.

We conclude that given the way Germanic languages have developed, with particular reference to developments with tangible effects as surveyed in section 2, phonological phrasings at the word level must have been available - or must indeed have been predominant in everyday speech - which were rhythmical, and in particular trochaic/dactylic, rather than being determined by surface syntax and morphology. Unless overridden by other considerations (like being in utterance-initial position with nothing to lean on), left word attachment of grammatical words and other weak material has been and continues to be the default in Germanic. Of course, special syntactic or prosodic considerations may block leftwards attachment.

How unusual is Germanic in point of phrasing? There has lately been some discussion of clitics whose phonological associations are at odds with their syntactic associations. The clitic typology of Klavans (1985) did provide for such split linguistic personalities; but they did not fit some theoretical frameworks and their existence was therefore denied or explained away (e.g. Embick \& Noyer 1999), while elsewhere it was reasserted (e.g. Cysouw 2005). There are terminological issues here, insofar as not any anti-syntactic 'leaner' was seen as qualifying for serious misfit status; additional criteria were imposed on 'ditropic' clitics, to do with the nature of their morphosyntactic association and the categorial non-specificity of their phonological hosts. Candidates under discussion included cross-referential pronouns, clausechaining markers, and nominal determiners and relational markers; and they were a motley crew language-wise, appearing to be prized finds from one language or another, hidden under masses of well-behaved clitics in the same languages. Now, whether Germanic has mere leftleaners or genuine ditropics, with rightwards morphosyntactic and leftwards phonological dependencies (and to us the right-facing morphosyntax of many enclitics would seem impeccable), what is remarkable, in light of this discussion, is how pervasive and systematic this mismatching is, and apparently has been for at least two millennia. One wonders how close-to-home and well-studied Germanic languages have managed to inspire (i) theories of phonological phrasing as solely or crucially determined by morphosyntactic constituency and (ii) typologies of clitics where matching morphosyntactic and phonological associations are the default or only option.

Now, Germanic is not unique in the pervasiveness of what has seemed to some approaches an aberration or impossibility; other families where at least a subset of members have been argued to pervasively mismatch phonological and morphosyntactic phrasings include IndoAryan, Uralic, Tibeto-Burman, Bantu, Penutian, and Wakashan. In the scheme of Milewski (1950), the latter have even won typological recognition as instantiating the 'cyclic' subtype of the 'excentric' type of relational dependent-marking, as opposed to the 'concentric' or headmarking type; and the characteristic phonological displacement of clitics from their syntactic co-constituents in relevant languages such as the Tsimshianic group or Kwak'wala has continued to be a theoretical challenge. For Bantu, a characteristic pattern of a mismatch between morphological and phonological wordhood, with nouns solidly prefixing in morphological structure, can be exemplified in (48):

(48) Teke-Kukuya (Bantu, Niger-Congo), as analysed by Hyman (1987) morphosyntactic phrasing: [Prefix-Stem [Prefix-Prefix-Stem]] phonological phrasing: $\quad$ Prefix $_{\text {extraprosodic }}\left(\operatorname{Stem}_{\text {Prefix }} \mathrm{pw}\right)\left(\operatorname{Stem}_{\mathrm{pW}}\right)$

$k_{I}-\left(l_{I} l_{I} \quad k i i-m \sigma_{\mathrm{pW}}\right)-\left(k a a y_{\mathrm{pW}}\right)$

CLASS-tear ASSOC-CLASS-Woman

'tear of the woman' 
Phonological wordhood ( $\mathrm{pW}$ ) is here motivated through tonal mapping patterns (lexical tone and postlexical tone, no spreading onto stem) and segmental distributions (consonant and vowel occurrences only definable over the domain (Stem Prefix); processes such as gemination). Among the Uralic languages where in-depth analyses are available, South Saami is reminiscent of Germanic insofar as 'accent phrases' are a major prosodic domain: they trochaically begin with a pitch-accented syllable, and unaccented words (discourse particles, copula verb) are generally associated leftwards regardless of syntactic constituency (Bye 2010). Such mismatching languages and families would seem to show a common denominator insofar as preposed function words and/or prefixes of morphosyntactic phrasing are enclitics in phonological phrasing; it is rarely, if ever (perhaps in Tibeto-Burman), the other way round, with postposed function words and/or suffixes of morphosyntactic phrasing as proclitics in phonological phrasing. ${ }^{30}$

There is probably something to be said for the wider validity of the trochaic/dactylic phrasing preference beyond Germanic and these other families; but we won't say it here. It would be of considerable interest, though, because it would help explain the near-universal preference for suffixing over prefixing. If it does not matter where grammatical words are positioned relative to the lexical words which they belong with syntactically, before or after, since phonologically they will always prefer to associate leftwards; and if cliticisation is what eventually leads to affixation - then the result will be suffixation rather than prefixation whatever the syntactic point of departure.

\section{ACKNOWLEDGEMENTS}

The cooperation that has led to this paper dates back to the times of SFB 471 at Konstanz, and with it the original funding through the Deutsche Forschungsgemeinschaft, for which we continue to be grateful. Earlier versions of the paper were presented orally on several occasions: the DGfS conference in Siegen in March 2007; the first Konstanz-Reykjavik (Oxford) Seminar in Reykjavik in May 2008 (KROSS 0); GLAC 15 in Banff in May 2009; the workshop Elements of Prosodic Structure at Queen Mary, University of London in March 2010; and the workshop Aspects of Prosody in Oxford in June 2010. We thank Janet Grijzenhout, Barış Kabak, Kristján Árnason, and Carlos Gussenhoven for getting us involved in these events, and the audiences for valuable feedback. Two anonymous reviewers for $T P h S$ offered constructive criticism, for which we are grateful. Without the patience of Louise Mycock and Nigel Vincent, these reviewers would have had nothing to review: we would like to thank our editors on their behalf. We are indebted to Paul Rowlett and Kate Dobson for putting the finishing touches to this work. Also, the authors, whose names appear in alphabetical order, wish to thank one another for taking the respective parts of the blame for remaining imperfections.

Aditi Lahiri

aditi.lahiri@ling-phil.ox.ac.uk

Frans Plank

frans.plank@uni-konstanz.de

\section{Abbreviations}

A adjective, ACC accusative, ACT active, ADV adverb, ASSOC associative, AUX auxiliary, CLASS classifier, COMP complementiser, CONJ conjunction, DAT dative, DEF definite, DET determiner, F feminine, GEN genitive, Gram grammatical/function word, INF infinitive, Lex

\footnotetext{
${ }^{30}$ Cysouw (2005) induces the same generalisation from his survey of ditropic clitics.
} 
lexical/content word, $\mathrm{M}$ masculine, MED middle, $\mathrm{N}$ noun, $\mathrm{N}$ neuter, NEG negation, NMB number, NOM nominative, NP noun phrase, OBJ object, PASs passive, PL plural, POSTP postposition, PREP preposition, PRO pronoun, PRS person, PRTCL particle, QU quantifier, REFL reflexive, SBJ subject, SG singular, TNS tense, TRANS transitiviser, V verb, VP verb phrase.

' $\bullet$ ' indicates an empty beat of a prosodic unit.

\section{REFERENCES}

Abercrombie, David, 1964a. 'A phonetician's view of verse structure', reprinted in David Abercrombie, Studies in Phonetics and Linguistics, London: Oxford University Press (1965), 16-25.

Abercrombie, David, 1964b. 'Syllable quantity and enclitics in English', reprinted in David Abercrombie, Studies in Phonetics and Linguistics, London: Oxford University Press (1965), 26-34.

BAyer, Josef, 2010. 'From modal particle to interrogative marker: a study of German denn', in Laura Brugè, Anna Cardinaletti, Giuliana Giusti, Nicola Munaro \& Cecilia Poletto (eds), Functional Heads: A Festschrift for Guglielmo Cinque, Oxford: Oxford University Press.

Berendsen, Egon, 1986. The Phonology of Cliticization, Dordrecht: Foris.

Blockley, Mary, 1988. 'Constraints on negative contraction with the finite verb and the syntax of Old English poetry', Studies in Philology 85, 428-50.

BLOCKLEY, MARY, 1990. 'Uncontracted negation as a cue to sentence structure in Old English verse', Journal of English and Germanic Philology 89, 475-90.

Bye, Patrik, 2010. 'Evidence for intonational phonology from South Saami', paper presented at 'Tone and Intonation in Europe 4', Stockholm, 11 September.

Cheng, C. C., 1973. A Synchronic Phonology of Mandarin Chinese, The Hague: Mouton.

Cutler, Anne, 1994. 'Segmentation problems, rhythmical solutions', Lingua 92, 81-104.

Cutler, Anne \& Norris, Dennis G., 1988. 'The role of stressed syllables in segmentation for lexical access', Journal of Experimental Psychology: Human Perception and Performance 14, 113-21.

Cysouw, Michael, 2005. 'Morphology in the wrong place: a survey of preposed enclitics', in Wolfgang U. Dressler et al. (eds), Morphology and its Demarcations: Selected Papers from the 11th Morphology Meeting, Amsterdam: Benjamins, 17-37.

De Pijper, Jan Roeloef \& Sanderman, Angelien A., 1994. 'On the perceptual strength of prosodic boundaries and its relation to suprasegmental cues', Journal of the Acoustical Society of America 96, 2037-47.

De Vogelaer, Gunther, 2010. 'Morphological change in continental West Germanic: towards an analogical map', Diachronica 27, 1-31.

De Vogelaer, Gunther \& van der Aumera, Johan, 2010. 'When typological rara generate rarissima: analogical extension of verbal agreement in Dutch dialects', in Jan Wohlgemuth \& Michael Cysouw (eds), Rara \& Rarissima: Documenting the Fringes of Linguistic Diversity, Berlin: Mouton de Gruyter.

Eisenberg, Peter, 1998. Grundriss der deutschen Grammatik, Band 1: Das Wort, Stuttgart: Metzler.

Embick, David \& Noyer, Rolf, 1999. 'Locality in post-syntactic operations', MIT Working Papers in Linguistics 34, 265-317.

Ferreira, Fernanda, 1991. 'The creation of prosody during sentence production', Psychological Review 100, 23353.

Fretheim, Thorstein, 1981. 'Intonational phrasing in Norwegian', Nordic Journal of Linguistics 4, 111-37.

Fretheim, Thorstein, 2001. 'The interaction of right-dislocated pronominals and intonational phrasing in Norwegian', in Wim A. van Dommelen \& Thorstein Fretheim (eds), Nordic Prosody: Proceedings of the 8th Conference, Trondheim 2000, Frankfurt am Main: Lang, 61-75.

Fudge, ERIK, 1999. 'Words and feet', Journal of Linguistics 35, 273-96.

Gee, James P. \& Grosjean, François, 1983. 'Performance structures: a psycholinguistic and linguistic appraisal', Cognitive Psychology 15, 411-58.

Grimm, JACOB, 1837. Deutsche grammatik, vol. 4, Göttingen: Dieterich.

Gimson, A. C., 1962. An Introduction to the Pronunciation of English, London: Arnold. (And subsequent editions.)

Gussenhoven, Carlos, 1986. 'Over de fonologie van Nederlandse clitica', Spektator 15, 180-200.

Howe, Stephen, 1996. The Personal Pronouns in the Germanic Languages: A Study of Personal Pronoun Morphology and Change in the Germanic Languages from the First Records to the Present Day, Berlin: de Gruyter.

Hyman, Larry M., 1987. 'Prosodic domains in Kukuya', Natural Language and Linguistic Theory 5, 311-33.

JACK, George, 1999. 'Negative contraction in Old English verse', Review of English Studies 50, $133-54$.

KabAK, Baris \& Schiering, René, 2006. 'The phonology and morphology of function word contractions in German', Journal of Comparative Germanic Linguistics 9, 53-99.

Klavans, Judith L., 1985. 'The independence of syntax and phonology in cliticization', Language 61, 95-120.

Kleist, Heinrich von, 1805. 'Über die allmähliche Verfertigung der Gedanken beim Reden', first published 1878. Available at Kleist-Archiv Sembdner, Heilbronn, http://www.kleist.org

Koopman, Willem F., 1997. 'Another look at clitics in Old English', Transactions of the Philological Society 95, 7393. 
Krähenmann, Astrid \& Plank, Frans, 2004. 'On definite articles in Upper German', paper presented at 'Word Domains: Theory and Typology', Leipzig, 7-8 April.

Kratzer, Angelika \& Selkirk, Elisabeth, 2007. 'Phase theory and prosodic spellout: the case of verbs', Linguistic Review 24, 93-135.

LAHIRI, Aditi, 2000. 'Hierarchical restructuring in the creation of verbal morphology in Bengali and Germanic: evidence from phonology', in Aditi Lahiri (ed.), Analogy, Levelling, Markedness: Principles of Change in Phonology and Morphology, Berlin: Mouton de Gruyter, 71-123.

Lahiri, Aditi, Jongman, Allard \& Sereno, Joan, 1990. 'The pronominal clitic [dər] in Dutch: a theoretical and experimental approach', Yearbook of Morphology 3, 115-27.

Lahiri, Aditi \& Kraehenmann, Astrid, 2004. 'On maintaining and extending contrasts: Notker's Anlautgesetz', Transactions of the Philological Society 102, 1-55.

Lahiri, Aditi, Wetterlin, Allison \& Jönsson-Steiner, Elisabet, 2005a. 'Lexical specification of tone in North Germanic', Nordic Journal of Linguistics 28, 61-96.

Lahiri, Aditi, Wetterlin, Allison \& Jönsson-Steiner, Elisabet, 2005b. 'Sounds definite-ly clitic: evidence from Scandinavian tone', Lingue e linguaggio 4, 243-62.

Levelt, Willem J. M., 1989. Speaking: From Intention to Articulation, Cambridge, MA: MIT Press.

Levin, Samuel R., 1958. 'Negative contraction: an Old and Middle English dialect criterion', Journal of English and Germanic Philology 57, 492-501.

Luick, KARL, 1923. Deutsche Lautlehre: Mit besonderer Berücksichtigung der Sprechweise Wiens und der österreichischen Alpenländer, 2nd edn, Leipzig: Deuticke.

Milewski, Tadeusz, 1950. 'La structure de la phrase dans les langues indigènes de l'Amérique du Nord', Lingua posnaniensis 2, 162-207. Reprinted in Tadeusz Milewski, Études typologiques sur les langues indigènes de l'Amérique, Cracow: Polska Akademia Nauk (1967), 70-101.

Nespor, Marina \& Vogel, Irene, 1986. Prosodic Phonology, Dordrecht: Foris. Reprinted, with a new foreword, Berlin: Mouton de Gruyter (2007).

Nübling, Damaris, 1992. Klitika im Deutschen: Schriftsprache, Umgangssprache, alemannische Dialekte, Tübingen: Narr.

Patel, Aniruddh D., 2008. Music, Language, and the Brain, Oxford: Oxford University Press.

Paul, Hermann, 1916-20. Deutsche Grammatik, 4 vols, Halle: Niemeyer.

Plank, Frans, 2003. 'Double articulation', in Frans Plank (ed.), Noun Phrase Structure in the Languages of Europe, Berlin: Mouton de Gruyter, 337-95.

Plank, Frans, 2005. '((FRISCH ge) (WAG tist)) ((HALB ge) (WON nen))', in Nanna Furhop (ed.), Festschrift für Peter Eisenberg, Potsdam: Universität Potsdam.

Price, Patti J., Ostendorf, Mari, Shattuck-Hufnagel, Stefanie \& Fong, Cynthia, 1991. 'The use of prosody in syntactic disambiguation', Journal of the Acoustical Society of America 90, 2956-70.

Saran, Franz, 1907. Deutsche Verslehre, Munich: Beck.

Saran, Franz, 1934. Deutsche Verskunst: Ein Handbuch für Schule, Sprechsaal, Bühne, Berlin: Junker Dünnhaupt.

Schiering, René, 2005. 'Flektierte Präpositionen im Deutschen? Neue Evidenz aus dem Ruhrgebiet', Zeitschrift für Dialektologie und Linguistik 72, 52-79.

Selkirk, Elisabeth O., 1984. Phonology and Syntax: The Relation Between Sound and Structure, Cambridge, MA: MIT Press.

Selkirk, Elisabeth O., 1995. 'The prosodic structure of function words', in Jill N. Beckman et al. (eds), Papers in Optimality Theory, Amherst: Dept of Linguistics, University of Massachusetts, 439-69. Reprinted in James Morgan \& Katherine Demuth (eds), Signal to Syntax: Bootstrapping from Speech to Grammar in Early Acquisition, Mahwah, NJ: Erlbaum (1996), 187-213.

Selkirk, Lisa \& Elordieta, Gorka, 2010. 'The role of prosodic markedness constraints in phonological phrase formation in two pitch accent languages', paper presented at 'Tone and Intonation in Europe 4', Stockholm, 9 September.

Shattuck-Hufnagel, Stefanie \& Turk, Alice E., 1996. 'A prosody tutorial for investigators of auditory sentence processing', Journal of Psycholinguistic Research 25, 193-247.

Sievers, EduARD, 1901a. Grundzüge der Phonetik: Zur Einführung in das Studium der Lautlehre der indogermanischen Sprachen, Leipzig: Breitkopf \& Haertel.

Sievers, Eduard, 1901b. 'Sprachgeschichte: Phonetik', in Hermann Paul (ed.), Grundriss der germanischen Philologie, 2nd edn, vol. 1, Strassburg: Trübner, 283-319.

Somers Wicka, Katerina, 2009. From Phonology to Syntax: Pronominal Cliticization in Otfrid's Evangelienbuch, Tübingen: Niemeyer.

Steele, Joshua, 1775. An Essay towards Establishing the Melody and Measure of Speech, London: J. Almon. (2nd edn: Prosodia rationalis, 1779. Reprint of 1st edn, Menston: Scolar Press, 1969.)

Sweet, Henry, 1876. Words, Logic and Grammar, London: Philological Society.

Sweet, Henry, 1877. Handbook of Phonetics, Oxford: Clarendon Press.

Sweet, Henry, 1885. Elementarbuch des gesprochenen Englisch, Leipzig: Tauchnitz. (3rd edn, 1904.)

Sweet, Henry, 1887. Second Middle English Primer: Extracts from Chaucer, Oxford: Clarendon Press.

Truckenbrodt, Hubert, 1999. 'On the relation between syntactic phrases and phonological phrases', Linguistic Inquiry 30, 219-55.

Truckenbrodt, Hubert, 2007. 'The syntax-phonology interface', in Paul de Lacy (ed.), The Cambridge Handbook of Phonology, Cambridge: Cambridge University Press, 435-56. 
Vogel, Irene, 2009. 'The status of the Clitic Group', in Janet Grijzenhout \& Barıs Kabak (eds), Phonological Domains: Universals and Deviations, Berlin: Mouton de Gruyter, 15-46.

Watson, Duane \& Gibson, Edward, 2004. 'The relationship between intonational phrasing and syntactic structure in language production', Language and Cognitive Processes 19, 713-55.

Weiss, Helmut, 2005. 'Inflected complementizers in continental West Germanic dialects', Zeitschrift für Dialektologie und Linguistik 72, 148-66.

Wenk, Brian J. \& Wiolland, François, 1982. 'Is French really syllable-timed?', Journal of Phonetics 10, $193-216$. Wheeldon, Linda \& Lahiri, Aditi, 1997. 'Prosodic units in speech production', Journal of Memory and Language 37 , $356-81$.

Wheeldon, Linda \& Lahiri, Aditi, 2002. 'The minimal unit of phonological encoding: prosodic or lexical word', Cognition 85, B31-41.

Wightman, Colin W., Shattuck-Hufnagel, Stefanie, Ostendorf, Mari \& Price, Patti J., 1992. 'Segmental durations in the vicinity of prosodic boundaries', Journal of the Acoustical Society of America 91, 1707-17.

Zwicky, Arnold M. \& Pullum, Geoffrey K., 1983. 'Cliticization vs. inflection: English n't', Language 59, 50213. 